\title{
A Influência da Cultura Organizacional na Primeira Instância da Justiça Federal
}

\author{
Aparecida Gonçalves Bandeira Pinto ${ }^{1}$; Andressa Pacífico Franco Quevedo ${ }^{2}$
}

\begin{abstract}
Resumo: Exige-se do Poder Judiciário uma prestação jurisdicional eficaz e eficiente em um prazo cada vez mais curto.Infelizmente, apenas algumas unidades jurisdicionais da primeira instância apresentam uma resposta satisfatória à sociedade. Dentre os aspectos a serem considerados em qualquer interferência na área de gestão que se proponha a fazer, chama especial atenção a cultura organizacional. Deste modo, o objeto deste estudo consiste na análise da influência da cultura organizacional no desempenho do primeiro grau do Poder Judiciário, especificamente na Justiça Federal. Para tanto, fez-se necessário se identificar os elementos que interferem na cultura organizacional, reconhecer os elementos que interferem na cultura organizacional no âmbito do primeiro grau do Poder Judiciário e, ainda, apontar ações que o gestor de uma unidade judiciária pertencente à Justiça Federal pode realizar, no âmbito da cultura organizacional, para melhorar o desempenho dessa unidade. Constatou-se, em resposta a essas indagações, pela revisão da literatura feita, que a alteração da cultura organizacional é viável e que o êxito dos arranjos institucionais alternativos está atrelado à aderência de elementos gerenciais inovadores aos valores e crenças já sedimentados.
\end{abstract}

Palavras-chave: Cultura organizacional. Justiça Federal de Primeira Instância. Desempenho.

\section{The influence of organizational culture on the first instance of the Federal Court}

\begin{abstract}
It is required of the judiciary an effective and efficient judicial services in a period shorter and shorter. Unfortunately, only a fewunits courts of first instance have a satisfactory answer to society. Among the aspects to be considered in any interference in the management area it intends to do, draws particular attention to organizational culture. Thus, the object of this study is to analyze the influence of organizational culture on performance of the first degree of the judiciary, particularly in the Federal Court. Therefore, it was necessary to identify the elements that interfere in the organizational culture, recognize the elements that interfere in the organizational culture within the first degree of the judiciary and also point out actions that the manager of a legal unit belonging to theFederal Court can perform within the organizational culture to improve the performance of this unit. It was noted, in response to these questions, the review of literature made, the change of organizational culture is feasible and that the success of alternative institutional arrangements is related to adhesion of innovative management elements to the values and beliefs already sedimented.
\end{abstract}

Keywords: Organizational culture. Federal Court of First Instance. Performance.

\section{Introdução}

Nesta sociedade globalizada, conectada, marcada por constantes inovações tecnológicas e insolúveis problemas no âmbito sócio-político-econômico em que se vive, a administração pública brasileira precisa se reinventar com mais frequência para acompanhar estes tempos marcados fortemente por mudanças. Nesta busca, o antagonismo entre "o novo e o velho" assume um papel relevante não só pelas possibilidades que se apresentam mas também pelos conflitos desencadeados.

\footnotetext{
${ }^{1}$ Pós-Graduanda em Gestão Pública pela Universidade Federal do Vale do São Francisco. Especialista em Direito Processual Civil pela Universidade Estadual do Ceará e em Direito Tributário pela Universidade Anhanguera - Uniderp, MBA em Poder Judiciário pela Fundação Getúlio Vargas - FGV. Analista Judiciária da Seção Judiciária do Ceará e Diretora de Secretaria da $17^{a}$ Vara Federal da Subseção Judiciária de Petrolina/PE. Contato autor correspondente - E-mail: cidagbandeira@ hotmail.com

${ }^{2}$ Mestre em Administração pela Universidade Federal de Pernambuco. Professora da Universidade Federal Rural de Pernambuco;
} 
Id on Line Revista Multidisciplinar e de Psicoloqia

Id on Line Revista Multidisciplinar e de Psicologia

Neste contexto, destacam-se as tensões vivenciadas pelo Poder Judiciário brasileiro. Este está dividido, nos termos da Constituição Federal de 1988, em primeiro grau, segundo grau e Tribunais Superiores. Cada instância distingue-se das demais, não só em competência, mas também em estrutura funcional.

Apesar de todos os esforços empreendidos nos últimos anos, ainda existe um grande descontentamento da sociedade em relação à qualidade dos serviços prestados pela Justiça brasileira. Assim, eficiência e celeridade se tornaram palavras de ordem em vários Tribunais e a tão propalada Reforma do Judiciário foi se tecendo dia após dia, ainda que sem o reconhecimento da sociedade e, por vezes, sem o devido amadurecimento.

Se boa parte do tempo de duração de um processo ocorre no primeiro grau, então não há por que se falar em qualidade da prestação jurisdicional negligenciando a qualidade dos serviços prestados em primeira instância. Decerto, de nada adiantaria medidas que repercutam apenas nas instâncias superiores, sobretudo porque o impacto das intervenções seria reduzido em face da quantidade de beneficiários atingidos.

Por outro lado, há de se reconhecer que promover qualquer alteração em um meio tão heterogêneo e pulverizado como o Poder Judiciário brasileiro exige muita reflexão e determinação. Ou seja, não basta legislação, treinamento, programa de valorização do servidor, revisão do plano de cargos e salários, etc. Assim, acredita-se que a mais consistente melhoria ocorrerá a partir de alterações no âmbito da cultura organizacional, uma vez que vários estudos revelam que esta interfere consideravelmente no desempenho da organização.

Cabe ao gestor de uma unidade judiciária, nesse cenário, identificar os elementos que podem contribuir para desenvolver uma cultura organizacional favorecedora da prestação jurisdicional de qualidade. Comumente,considera-se que um bom serviço jurisdicional é prestado quando, de forma eficiente, são evitadas as digressões desnecessárias na tramitação do processo, sempre visando resolver o litígio de forma definitiva. Para se alcançar tal objetivo, somente mudanças na legislação e o preparo jurídico do gestor e servidores não são suficientes, o que implica dizer que muitas medidas na área de gestão precisam ser adotadas e, se de fato, busca-se um realinhamento de ordem estrutural, deve-se preocupar com a cultura organizacional, um elemento intangível e dinâmico.

Por outro lado, quando se cogita em realizar mudança na organização, o que é inevitável em nosso cotidiano, é indispensável se avaliar o impacto dessas alterações no contexto cultural em que está inserida essa organização. Isso deve ser considerado, sobretudo, quando estamos tratando de um ambiente como o Judiciário, que é notoriamente formal. Assim, impõe-se questionar qual a influência da cultura organizacional no desempenho do primeiro grau do Poder Judiciário, especificamente na Justiça Federal.

Como desdobramento dessa indagação, urge, em primeiro lugar, identificar os elementos que interferem na cultura organizacional; em segundo lugar, reconhecer os elementos que interferem na 
Id on Line Revista Multidisciplinar e de Psicologia

Id on Line Revista Multidisciplinar e de Psicologia

cultura organizacional no âmbito do primeiro grau do Poder Judiciário; e, em terceiro lugar, apontar ações que o gestor de uma unidade judiciária pertencente à Justiça Federal pode realizar, no âmbito da cultura organizacional, para melhorar o desempenho dessa unidade.

Para tanto, este artigo propõe-se a fazer uma revisão crítica da literatura existente sobre o tema, de modo a situar as contribuições teóricas, seja de autores focados na área privada seja de autores voltados para a área pública, no âmbito da Justiça Federal de Primeira Instância.

\section{Os elementos que interferem na cultura organizacional}

Antes de aprofundar o estudo acerca da cultura organizacional, urge que se reflita sobre a definição dessa expressão. Para tanto, há de se reconhecer que a palavra culturaassume diversos significados, todos relacionados ao sentido etimológico do termo, ou seja, ao cultivo das plantações. Com o passar dos anos, por meio de um processo de analogia, referido termo foi sendo relacionado ao desenvolvimento intelectual e educacional das pessoas.

Uma das acepções mais frequente do termo na atualidade foi apreendida por Fleury e Fischer (1989, p. 117):

A cultura é concebida como um conjunto de valores e pressupostos básicos expresso em elementos simbólicos, que em sua capacidade de ordenar, atribuir significações, construir a identidade organizacional, tanto age como elemento de comunicação e consenso, como oculta e instrumentaliza as relações de dominação.

Infere-se, assim, que a cultura se forma a partir da interação do homem no grupo em que convive, daí emergindo os valores, as crenças, os conhecimentos, os costumes, as instituições, os quais variam no tempo e no espaço, de acordo com a dinâmica da própria sociedade.

A expressão cultura organizacional, por seu turno, possui uma origem de natureza antropológica e sociológica, conforme explicita Carvalho (2015, p. 61):

Já o conceito de cultura organizacional emergiu, inicialmente, de duas raízes disciplinares: uma de fundamentação antropológica, para a qual asorganizaçõessão culturas; e outra de fundamentação sociológica, para a qual as organizações têm culturas. Inseridas nestas disciplinas, foram desenvolvidas duas aproximações diferentes para cultura: a funcional, na qual as culturas emergem do comportamento coletivo; e a semiótica, na qual as culturas residem nas interpretações cognitivas e individuais (CAMERON; QUINN, 1999).

Pires e Macêdo (2006, p. 87) historiam que o termo cultura organizacional surgiu na literatura de língua inglesa nos anos 1960, como sinônimo de clima. Acrescentam, ainda, que, em 1982, foi 
Id on Line Revista Multidisciplinar e de Psicologia

Id on Line Revista Multidisciplinar e de Psicologia

publicado o livro intitulado Cultura Corporativa, de TerrenceDeal e Allan Kennedy, o qual reforçou o uso do termo pela literatura técnica.

Ante a inexistência de um conceito clássico para o termo e a diversidade de estudos existentes, adotamos para fins deste trabalho as ideias trazidas por Schein, sintetizadas por Carvalho (2015, p. $62)$ :

Schein (1985) define cultura organizacional como um conjunto de premissas básicas, tais como conceitos, princípios, regras, formas de comportamento e soluções, que foram estabelecidas e descobertas, no processo de aprendizagem de solução de problemas de adaptação externa e integração interna e por funcionarem suficientemente bem, foram consideradas válidas e ensinadas aos outros membros da organização como a maneira certa de agir em relação a esses problemas.

Pela abrangência da definição, há de se concordar que se trata de um conceito descritivo (ROBBINS, 2005, p. 376) e com significativo grau de elasticidade (BERGUE, 2010, p. 22), no qual se destaca o compartilhamento de certas características entre os integrantes da organização de tal ordem que é capaz de individualizar a referida organização entre todas as outras.

Conforme pontua Pires e Macêdo (2006, p. 85-86), as organizações brasileiras possuem características próprias que se distinguem de outras culturas e de outros países, refletindo os valores culturais da sociedade em que está inserida. Ressalta, na oportunidade, que os valores culturais são transmitidos pelo processo de socialização e consolidados com sua prática social no cotidiano das instituições sociais como família, escola, religião e nas organizações.

No que diz respeito às organizações públicas brasileiras, Bergue $(2010$, p. 24) identificou os seguintes traços culturais de comportamento nas organizações que podem ser generalizados, variando o grau de intensidade conforme a situação, de modo a se construir um arranjo cultural único: a ênfase nas relações pessoais e de grupos; a reduzida suscetibilidade do ambiente a turbulências; a constância no ritmo e dinâmica de trabalho; o reduzido grau de insegurança em termos de manutenção do vínculo laboral (estabilidade); a valorização seletiva dos padrões formais; o corporativismo; e a condescendência.

Assim, antes de se debruçar sobre esses elementos culturais de comportamento nas organizações públicas, urge se fazer uma digressão histórica com o intuito de se analisar a trajetória da administração pública brasileira e melhor contextualizá-la. Inicialmente, há de se convir que, segundo Keinert (1994, apud BERGUE, 2010, p. 35), há quatro ciclos paradigmáticos na Administração Pública brasileira no século XX (1900 a 1990): a Administração Pública como ciência jurídica (19001929); a Administração Pública como ciência administrativa (1930-1979); a Administração Pública como ciência política (1980-1989); e a administração pública como Administração Pública (a partir de 1989). 
Id on Line Revista Multidisciplinar e de Psicoloqia

Id on Line Revista Multidisciplinar e de Psicologia

Esses ciclos de mudança organizacional ocorreram à medida que reformas do Estado e da sua administração foram se concretizando e, como todo processo de mudança, foi marcado por avanços, retrocessos e contradições.

Na evolução desses ciclos renovatórios, podemos identificar, conforme apontado por Klering, Porsse e Guadagnin (2010, p. 5), a existência de três modelos básicos de administração: a patrimonialista, a burocrática e a gerencial. Segundo mencionados autores (2010, p. 5-6), no modelo da administração pública patrimonialista não há distinção entre o público e o privado, funcionando o aparelho do Estado como uma extensão do poder soberano. A administração pública burocrática, por sua vez, é particularizada pelas ideias de profissionalização, carreira, hierarquia funcional, impessoalidade e formalismo, na qual se destacam controles rígidos dos processos, ineficiência, autorreferência e incapacidade de voltar-se para o serviço aos cidadãos. E, por fim, a partir da edição do Decreto-Lei n. ${ }^{\circ}$ 200/1967, procurou-se superar a rigidez burocrática conferindo maior dinamismo operacional à Administração Pública por meio das ideias gerenciais.

Quando se olha para o futuro, há de se concordar com Abrucio (2007, p. 79), que propõe passar a renovação da agenda de reformas no âmbito da modernização do Estado brasileiro por quatro eixos estratégicos: profissionalização, eficiência, efetividade e transparência/accountability. Por essa perspectiva, vê-se que os elementos apontados estão intrinsecamente relacionados à cultura organizacional.

De fato, segundo os estudos desenvolvidos por Schein(1992, apud CHIAVENATO, 2004, p. 167), os elementos que compõem a cultura organizacional manifestam-se em três níveis:

Primeiro nível: estão os artefatos, que correspondem às coisas ou eventos que podem nos indicar visual ou auditivamente como é a organização com a qual nos deparamos. Aqui se incluem os produtos, serviços e padrões de comportamento dos membros de uma organização. Constitui o nível mais superficial, visível e perceptível.

Segundo nível: estão os valores compartilhados, ou seja, aquilo que se tornou importante para as pessoas e que definem as razões pelas quais elas agem de determinada maneira.

Terceiro nível: estão as pressuposições básicas, entendidas como as crenças inconscientes, percepções, sentimentos e pressuposições dominantes e nos quais as pessoas acreditam. É o nível mais íntimo, Profundo e oculto da cultura organizacional.

Assim, a complexa relação entre esses três níveis definirá como se apresenta a cultura organizacional. Ao longo do tempo, a experiência adquirida pelos membros de uma organização, compartilhada e validada pela prática passa a nortear o modo de pensar e fazer de todos, de maneira a construir a identidade da organização.

Baseando-se nesses três níveis, Chiavenato (2004, p. 168) elenca os principais elementos da cultura organizacional: 
1. O cotidiano do comportamento observável. Como as pessoas interagem, a linguagem e gestos utilizados, os rituais, rotinas e procedimentos comuns.

2. As normas. Ou regras que envolvem os grupos e seus comportamentos, como nos momentos de lazer, nas refeições, nos dias informais.

3. Os valores dominantes. Defendidos por uma organização, como a ética, o respeito pelas pessoas, a qualidade de seus produtos ou preços baixos.

4. A filosofia administrativa. Que guia e orienta as políticas da organização quanto aos funcionários, clientes e acionistas.

5. As regras do jogo. Como as coisas funcionam, o que um novo funcionário deve aprender para sair-se bem e ser aceito como membro de um grupo.

6. O clima organizacional. Os sentimentos das pessoas e a maneira como elas interagem entre si, com os clientes ou elementos externos.

Pelo exposto, vê-se que a cultura organizacional influencia fortemente o cotidiano das organizações, interferindo não só em seu próprio desempenho, mas na vida de cada um dos seus membros. Qualquer mudança que se proponha em uma organização, para ser bem-sucedida, há de considerar a apresentação dos três diferentes níveis da cultura organizacional e, sobretudo, que a interferência nas estruturas e processos organizacionais visíveis é mais fácil, aumentando o grau de dificuldade quando passamos para o segundo nível e mais ainda para o terceiro.

\section{A estrutura organizacional da Justiça Federal de primeira instância}

A Constituição Federal de 1988 relaciona, no art. 92, os órgãos do Poder Judiciário: o Supremo Tribunal Federal, o Conselho Nacional de Justiça, o Superior Tribunal de Justiça, os Tribunais Regionais Federais e Juízes Federais, os Tribunais e Juízes do Trabalho, os Tribunais e Juízes Eleitorais, os Tribunais e Juízes Militares e os Juízes dos Estados e do Distrito Federal e Territórios.

Na organização estrutural delineada, a Justiça Federal comum é formada pelo Tribunal Regional Federal, na segunda instância, e pelos juízes federais, na primeira instância, competindo a estes, nos termos do art. 109 da Constituição Federal de 1988, processar e julgar as causas em que a União, entidade autárquica ou empresa pública federal forem interessadas na condição de autoras, rés, assistentes ou oponentes, exceto as de falência, as de acidentes de trabalho e as sujeitas à Justiça Eleitoral e à Justiça do Trabalho; as causas entre Estado estrangeiro ou organismo internacional e Município ou pessoa domiciliada ou residente no País; as causas fundadas em tratado ou contrato da União com Estado estrangeiro ou organismo internacional; os crimes políticos e as infrações penais praticadas em detrimento de bens, serviços ou interesse da União ou de suas entidades autárquicas ou empresas públicas, excluídas as contravenções e ressalvada a competência da Justiça Militar e da Justiça Eleitoral; os crimes previstos em tratado ou convenção internacional, quando, iniciada a execução no País, o resultado tenha ou devesse ter ocorrido no estrangeiro, ou reciprocamente; os 
Id on Line Revista Multidisciplinar e de Psicologia

Id on Line Revista Multidisciplinar e de Psicologia

crimes contra a organização do trabalho e, nos casos determinados por lei, contra o sistema financeiro e a ordem econômico-financeira; os habeas corpus, em matéria criminal de sua competência ou quando o constrangimento provier de autoridade cujos atos não estejam diretamente sujeitos a outra jurisdição; os mandados de segurança e os habeas data contra ato de autoridade federal, excetuados os casos de competências dos tribunais federais; os crimes cometidos a bordo de navios ou aeronaves, ressalvada a competência da Justiça Militar; os crimes de ingresso ou permanência irregular de estrangeiro, a execução de carta rogatória, após o exequatur, e de sentença estrangeira, após a homologação, as causas referentes à nacionalidade, inclusive a respectiva opção, e à naturalização e a disputa sobre direitos indígenas.

Para desempenhar esse mister, cada Estado, assim como o Distrito Federal, constitui uma Seção Judiciária cuja sede é a respectiva Capital, conforme previsto na Lei 5.010/1966. Nas principais cidades do interior, ficam as Subseções Judiciárias que são formadas, pelo menos, por uma Vara Federal, conforme a previsão legal. Toda Seção Judiciária está sob a jurisdição de um Tribunal Regional Federal.

Cada Vara conta com um Juiz Federal Titular, que exerce não só a função jurisdicional mas também a administração da Vara, e um Juiz Substituto, nomeados pelo Tribunal respectivo. Os magistrados são auxiliados por servidores públicos (pertencentes ao quadro de servidores do Tribunal ou requisitados), estagiários e, talvez, terceirizados. Todos os cargos efetivos, cargos em comissão e funções comissionadas são criados por lei.

Segundo Celso Antônio Bandeira de Mello (2014, p. 255-256), são servidores públicos aqueles que mantêm vínculos de trabalho profissional com o Estado e com as pessoas de Direito Público da Administração indireta e caráter não eventual sob vínculo de dependência.

No caso do Poder Judiciário Federal, após aprovação em concurso público promovido pelo Tribunal Regional Federal ao qual está subordinada a Seção Judiciária, os servidores sujeitam-se ao regime estatutário e ocupam cargos públicos criados por lei, a qual define também as atribuições do cargo e fixa o padrão de vencimento ou remuneração.

Os servidores requisitados, por sua vez, são servidores públicos pertencentes aos quadros da Administração Pública Federal direta, suas autarquias e fundações que estão cedidos à Justiça Federal nos termos do art. 93 da Lei 8.112/90 e do art. $2 .^{\circ}$ do Decreto 4.050/2001. Para que isso ocorra, é necessário que esse servidor receba uma função. Entende-se por esta as atribuições correspondentes a encargos de chefia, direção, assessoramento ou outro tipo de atividade para o qual o legislador não crie o cargo respectivo, a qual deve ser exercida exclusivamente por servidores ocupantes de cargo efetivo (DI PIETRO, 2014, p. 606).

Há previsão, ainda, de um único cargo em comissão, o qual é ocupado pelo(a) Diretor(a) de Secretaria. Nesse caso, o titular do cargo não precisa ter sido aprovado em um concurso público, sendo indicado pelo Juiz Titular que pode exonerá-lo livremente. 
Os estudantes de Direito podem submeter-se a estágio que possui caráter educativo complementar, nos termos da Lei n. ${ }^{\circ} 11.788 / 2008$, no qual deve ser equalizada a contribuição que o estagiário pode dar à instituição e o que esta pode retribuí-lo em termos de experiência de aprendizado.

Os terceirizados restringem-se às áreas de vigilância, conservação e limpeza e, ainda, aos serviços especializados ligados à atividade-meio, em respeito à Súmula n. ${ }^{\circ} 331$ do Tribunal Superior do Trabalho.

Assim, cada novo membro da primeira instância da Justiça Federal, quase todos após submeter-se a um concurso público, passa a vivenciar um processo chamado de socialização organizacional, por meio do qual, no caso específico, a Vara Federal procura integrar o ingressante à sua cultura, ao seu contexto e ao seu sistema, para que ele venha a comportar-se da maneira adequada às expectativas da organização (CHIAVENATO, 2004, p. 173).

É preciso se considerar, ainda, que esses atores estão submetidos a uma crescente demanda processual e que a sociedade anseia por uma maior e melhor prestação jurisdicional. Paralelamente, esses atores enfrentam frequentes modificações legislativas e questões inovadoras sob o prisma jurídico.

Qualquer mudança que o gestor queira promover há de considerar essas condições. E mais, cada unidade jurisdicional, embora possua estrutura semelhante, seja no tocante ao espaço físico, seja na distribuição do número de magistrados, servidores, estagiários e terceirizados, seja na divisão em setores, seja nas relações de subordinação, distingue-se uma da outra por possuir identidade própria, uma essência única. Cabe ao gestor ter sensibilidade para reconhecer essas especificidades e, a partir daí, direcionar suas ações para o alcance dos objetivos organizacionais.

\section{Ações gerenciais, no âmbito da cultura organizacional, visando melhorias do desempenho de uma unidade judiciária}

O Juiz Federal assume uma Vara Federal quando esta foi instalada ou, mais frequentemente, quando há mudança no titular da Vara. Na primeira situação, ele juntamente com os servidores que vão compor o quadro de funcionários passam a desenvolver a cultura organizacional daquela unidade, enquanto que, na segunda situação, esta já existe.

Cabe, assim, ao Juiz Titular além das atribuições jurisdicionais também as administrativas pertinentes à gestão da Vara. Estas são sumamente importantes, pois possibilitam a prática dos atos 
necessários para a concretização dos provimentos judiciais. Sobre esta responsabilidade, pondera Carlos Roberto Faleiros Diniz (2003, p. 30):

\begin{abstract}
Por outras palavras, portanto, o juiz é o principal agente da reforma administrativa do Poder Judiciário. Na qualidade de administrador das varas e tribunais, é o juiz quem deve ter a visão global de gestão e promover as mudanças necessárias para reverter o crítico quadro do Judiciário. Outrossim, destaca-se que a autoridade e a legitimidade do juiz para conduzir essas mudanças têm fundamento no próprio ordenamento jurídico, que coloca em suas mãos a tarefa de assegurar a qualidade e a eficácia na prestação jurisdicional (BIELSA, 1996, p. 14).
\end{abstract}

Em que pese ser evidente a necessidade do Juiz Titular possuir conhecimentos na área jurídica e administrativa, até assumir a titularidade da Vara só lhe foi exigido demonstrar conhecimentos jurídicos, até porque a formação acadêmica que lhe foi dada restringiu-se ao âmbito do Direito. Evidencia-se, dessa forma, a ausência de interdisciplinaridade, o descompasso entre a preparação técnica e a exigência da prática cotidiana, sendo forçoso reconhecer que a maioria adotará método empírico no dia a dia.

Na tentativa de minimizar essa lacuna de conhecimento, alguns Tribunais passaram a oferecer cursos voltados para a área de gestão, o que, em certa medida, tem o condão de despertar os Magistrados para as questões administrativas, frequentemente consideradas de importância menor.

A par disso, há de se ter em mente que não basta transpor para a administração pública os ensinamentos da área privada, de forma acrítica, sem atentar para as peculiaridades daquela (BERGUE, 2010, p. 29). A transposição de qualquer tecnologia da área de gestão para a administração pública está adstrita ao uso de um filtro pelo gestor, sob pena de não existir aderência entre os elementos culturais que se pretende introduzir ao contexto público (BERGUE, 2010, p. 84). Carbone (2010, p. 3) relaciona os seguintes fatores que dificultam a mudança no setor público brasileiro: burocratismo, autoritarismo/centralização, aversão aos empreendedores, paternalismo, levar vantagem, reformismo. Carbone (1996, p. 99) sintetiza as dificuldades enfrentadas pelo gestor público brasileiro que busca empreender nos seguintes termos:

Não podemos esquecer que, com raras e honrosas exceções, os movimentos de reforma no Brasil são, histórica e culturalmente, atrelados à luta de espaços por poder. O discurso é modernizante e arrojado, mas a prática é exatamente o contrário. Os empreendedores - principalmente do setor público - sabem disso; daí o descrédito das reformas. Sabem, também, que, por dominarem espaços técnicos e negociais muitas vezes poderosos, estão sempre em evidência, sendo alvo de desconfianças e ciúmes generalizados. Nesse cenário é comum, no Brasil, a neutralização temporária das atividades do empreendedor, quebrando a continuidade de seus serviços. Desmotivados e excluídos, os empreendedores estão limitados a poucos caminhos: renunciam e ficam olhando o "barco pegar fogo" ou então partem para seus negócios particulares, usando a empresa estatal ou o órgão público apenas como retaguarda econômica e garantia da segurança familiar. 
De toda forma, independente do grau de conhecimento e interesse sobre os assuntos organizacionais, o Juiz Federal titular de uma Vara Federal precisará geri-la e influenciará e será influenciado pela cultura organizacional. O ambiente de trabalho em que opera o Poder Judiciário possui relativa estabilidade. No entanto, muitas vezes, os objetivos organizacionais e individuais são divergentes. O Magistrado enfrentará limitações em seu autuar decorrentes da legislação, da resistência de seus superiores, pares e subordinados, da sobrecarga de trabalho, além de recursos públicos escassos. No que concerne à resistência à mudança, não se pode perder de vista as seguintes ponderações de Bergue (2010, p. 51):

A resistência à mudança precisa ser compreendida a partir de um sistema de resultados. Para tanto precisamos compreender que as pessoas, em geral, são capazes de, diante de uma mudança iminente ou potencial, efetuar uma avaliação que resulte em um quantum de perda pessoal em relação ao espaço e patrimônio pessoal que já foi conquistado. Além de uma expectativa de perda futura frente ao que uma trajetória projetada reserva em termos de ganhos previstos de qualquer ordem.

Essa 'perda' precisa ser compreendida em sua acepção estendida, ou seja, envolvendo não somente a dimensão econômica ou financeira, mas incorporando, especialmente, aspectos afetos ao status da pessoa na organização, espaços de poder, perspectivas futuras de atuação, até esferas mais íntimas da personalidade, tais como o orgulho e a imagem percebida, entre outros.

Outra dimensão de perda a ser considerada pelas pessoas como ensejadoras de ações de resistência aos processos de mudança são os riscos de afetação das condições que conferem estabilidade (segurança) às pessoas em relação aos processos e ambiente de trabalho.

Nessa linha, podemos afirmar que a resistência à mudança esta (sic) relacionada, eminentemente, no resultado de uma contabilização de perdas e ganhos potenciais que possam decorrer de uma inovação introduzida por um processo de mudança. A resistência à mudança pode ser minimizada, ou mesmo elidida, se o indivíduo ou grupo destinatário da mudança for capaz de constatar resultado positivo no balanço de perdas e ganhos decorrentes da inovação.

$\mathrm{Na}$ condução de mudanças organizacionais, o gestor corre o risco de atribuir a culpa pelas ineficiências administrativas e pelos fracassos na mudança à cultura organizacional, ignorando as especificidades que envolvem o caso concreto, como bem evidencia Motta (2001, p. 106 e 107):

A aplicação do conceito de cultura à mudança organizacional merece cautela, pois tende a sofrer das mesmas dificuldades de quando aplicado a povos e grupos sociais maiores. Por ser muito amplo, o conceito de cultura se presta como categoria residual: fornece explicação onde faltam conhecimentos mais apurados. Tornou-se lugar-comum culpar a cultura pelas ineficiências administrativas, ou mesmo pelos fracassos na mudança. Antes de admitir deficiências em seus modelos técnicos ou nas inabilidades gerenciais, gestores e consultores isentam-se de responsabilidade simplesmente por culparem a cultura da empresa onde atuam. A amplitude do conceito facilita explicações genéricas sem a menção de fatores específicos ou identificáveis por categorias não-culturais de análise. 
Id on Line Revista Multidisciplinar e de Psicologia

Id on Line Revista Multidisciplinar e de Psicologia

Outro desafio consiste em conciliar a rotina da organização com as ações tendentes à implementação de mudanças. Essa dificuldade decorre das exigências do plano operacional que, muitas vezes, ocupam tal dimensão a ponto de reclamar toda a atenção do dirigente. Se não houver, portanto, um forte e consistente comprometimento com as propostas de melhoria, infelizmente, estas podem ser deixadas de lado e tudo o que foi construído encaminha-se para cair no esquecimento, o que demandará um esforço maior ainda para restaurar essas ideias e, principalmente, para introduzir, mais uma vez, inovações gerenciais de qualquer ordem.

Não se pode ignorar, por outro lado, que vetores de mudança impactam o contexto organizacional. A absorção de elementos culturais novos advém muitas vezes da necessidade de resolver tensões desencadeadas por fatores externos: pressões sociais por uma melhor prestação jurisdicional, necessidade de utilização de novas tecnologias, contingenciamento de gastos, etc.

Qualquer movimento objetivando a transformação organizacional deve ser precedido de uma franca comunicação entre o gestor e a equipe de trabalho, sob pena de uma falha na mensagem repercutir negativamente na ação gerencial. Deve-se, assim, manter-se em permanência vigilância o processo de comunicação.

Apesar de todos os percalços que podem ser enfrentados, há de se ter em mente que a cultura organizacional pode ser alterada. Chiavenato (2004, p. 173) destaca que este é um processo lento e que a mudança está mais susceptível de ocorrer em uma das seguintes hipóteses: crise dramática, modificações na liderança, organização pequena e jovem ou cultura fraca. Compete ao gestor, dessa forma, realizar uma análise crítica da situação e avaliar se a oportunidade que se apresenta não traz as condições favoráveis para o início das modificações desejadas. Configurado um cenário promissor, Chiavenato (2004, p. 173) sugere ao gestor adotar as seguintes iniciativas:

1. Os dirigentes devem assumir papéis positivos dando o tom de sua conduta.

2. Devem criar novas histórias, símbolos e rituais para substituir os atuais.

3. Selecionar, promover e apoiar empregados que adotam novos valores.

4. Redesenhar os processos de socialização e alinhá-los com novos valores.

5. Mudar o sistema de recompensas para obter aceitação dos novos valores.

6. Substituir normas não-escritas por novas regras e regulamentos impostos.

7. Agitar as subculturas com transferências de pessoas, rotação de cargos e/ou demissões.

8. Trabalhar com o consenso de grupos utilizando a participação dos funcionários e criação de um clima de alto nível de confiança.

Indispensável, ainda, admitir-se que, quanto mais a cultura organizacional for favorável aos propósitos do gestor, mais fácil lhe será desempenhar seu papel. A adoção de modelos gerenciais precisa estar compatível com o conjunto de valores da organização, sob pena de prejudicar consideravelmente a instituição. Nesse contexto, não há que se cogitar em soluções padronizadas. Ignorar os elementos da cultura organizacional pode constituir um fator determinante do fracasso de 
Id on Line Revista Multidisciplinar e de Psicologia

Id on Line Revista Multidisciplinar e de Psicologia

um projeto de mudança. Da mesma forma que a cultura organizacional pode ser um limitador da eficiência e eficácia de uma organização pode também constituir-se como um diferencial positivo na busca pelas melhorias a serem implementadas.

\section{Conclusões}

Este artigo teve como objetivo analisar a influência da cultura organizacional no desempenho do primeiro grau do Poder Judiciário, especificamente na Justiça Federal de Primeira Instância. Para tanto, valeu-se da revisão da literatura para fundamentar o referencial teórico.

Viu-se que cabe ao Poder Judiciário, a quem incumbe desenvolver a prestação jurisdicional de modo privativo, buscar atender as expectativas de uma sociedade cada vez mais exigente. Nesse contexto, urge se buscar novas tecnologias gerenciais, visando garantir a eficiência e a eficácia do Judiciário, sobretudo porque se depende de recursos públicos escassos, possui o gestor um poder de decisão restrito à área de jurisdição em que atua e está adstrito às determinações provenientes do tribunal e aos normativos legais e constitucionais.

Dentre os aspectos que podem favorecer o desempenho da Justiça Federal de Primeira Instância, o estudo concentrou-se na perspectiva cultural da organização, cujo foco está naquilo que é compartilhado pela equipe de trabalho e não nas atitudes e comportamentos individualizados de cada membro.

$\mathrm{Na}$ complexidade e dinamismo da cultura organizacional, evidenciou-se que o êxito de arranjos institucionais alternativos está atrelado à aderência de elementos gerenciais inovadores aos valores e crenças já sedimentados. Qualquer alteração nos traços culturais de uma organização implica mudança de fatores de identidade, daí a necessidade de legitimação do processo de mudança organizacional.

A cultura organizacional, por outro lado, carrega a coerência indispensável para se conferir sentido de direcionamento à organização, razão pela qual precisa estar alinhada com as inovações gerenciais a serem introduzidas. Inegável, assim, que a mudança nas organizações, como em qualquer outra dimensão, é um processo contínuo, ainda que imperceptível no cotidiano.

As limitações desse estudo apontam que, para estudos futuros, é importante se valer de pesquisas que possibilitem validar ou refutar as ideias apresentadas na prática cotidiana da Justiça Federal de Primeira Instância, em todos os Tribunais que a compõem, tanto por seus Magistrados como por seus servidores.

Finalmente, espera-se que as reflexões desencadeadas por este trabalho possam mobilizar os gestores das unidades judiciárias a considerarem a cultura organizacional como um fator de suma importância para o alcance das estratégias traçadas. 
Id on Line Revista Multidisciplinar e de Psicoloqia

Id on Line Revista Multidisciplinar e de Psicologia

\section{Referências}

ABRUCIO, Fernando Luiz. Trajetória recente da gestão pública brasileira: um balanço crítico e a renovação da agenda de reformas. Revista da Administração Pública, Rio de Janeiro, edição especial comemorativa, p. 67-86, 1967-2007.

BERGUE, Sandro Trescastro. Cultura e mudança organizacional. Florianópolis: Departamento de Ciências da Administração/UFSC, 2010.

BRASIL. Constituição da República Federativa do Brasil (1988). Disponível em: < http://www.planalto.gov.br/ccivil_03/Constituicao/Constituicao.htm>. Acesso em: 19 abr. 2016.

Decreto n. ${ }^{\circ}$ 4.050, de 12 de dezembro de 2001. Disponível em: <http://www.planalto.gov.br/ccivil_03/decreto/2001/D4050.htm >. Acesso em: 22 abr. 2016.

Lei n. ${ }^{0}$ 5.010, de 30 de maio de 1966. Disponível em: <http://www.planalto.gov.br/ccivil_03/leis/L5010.htm>. Acesso em: 22 abr. 2016.

Lei n. ${ }^{0}$ 8.112, de 11 de dezembro de 1990. Disponível em: <http://www.planalto.gov.br/CCIVIL_03/leis/L8112cons.htm>. Acesso em: 22 abr. 2016.

Lei n. ${ }^{\circ}$ 11.788, de 25 de setembro de 2008. Disponível em: < http://www.planalto.gov.br/ccivil_03/_ato2007-2010/2008/lei/111788.htm>. Acesso em: 22 abr. 2016.

Tribunal Superior do Trabalho. Súmula n. ${ }^{0}$ 331. Disponível em: < http://www3.tst.jus.br/jurisprudencia/Sumulas_com_indice/Sumulas_Ind_301_350.html\#SUM-331>. Acesso em: 22 abr. 2016.

CARBONE, Pedro Paulo. Cultura organizacional do setor público brasileiro: desenvolvendo uma metodologia de gerenciamento da cultura. Revista de Administração Pública, Rio de Janeiro, v. 34, n. 2, p. 133-144, mar./abr. 2000.

Os herois do setor público: a teia cultural engolindo o empreendedor. Revista de Administração Pública, Rio de Janeiro, v. 30, n. 3, p. 93-102, maio/jun. 1996.

CARVALHO, Liza Fachin de. Análise da cultura organizacional no gerenciamento de projetos. 2015. 168 f. Dissertação (Mestrado em Engenharia de Produção e Área de Concentração em Processos e Gestão de Operações)-Escola de Engenharia de São Carlos da Universidade de São Paulo. São Paulo, 2015.

CHIAVENATO, Idalberto. Gestão de pessoas: e o novo papel dos recursos humanos nas organizações. 2. ed. Rio de Janeiro: Elsevier, 2004.

DINIZ, Carlos Roberto Faleiros. Gestão Administrativo e Reforma do Poder Judiciário. Revista Síntese de Direito Civil e Processual Civil, Porto Alegre, v. 4, n. 23, p. 24-34, maio/jun. 2003.

DI PIETRO, Maria Sylvia Zanella. Direito Administrativo. 27. ed. São Paulo: Atlas, 2014.

FLEURY, M.T.; FISCHER, R. M. Cultura e poder nas organizações. São Paulo: Atlas, 1989. 
Id on Line Revista Multidisciplinar e de Psicoloqia

Id on Line Revista Multidisciplinar e de Psicologia

KLERING, L. R.; PORSSE, M. C. S.; GUADAGNIN, L. A. Novos caminhos da administração pública brasileira. Análise, Porto Alegre, v. 21, n. 1, p. 4-17, jan.jun. 2010.

MELlO, Celso Antônio Bandeira de. Curso de Direito Administrativo. 32. ed. São Paulo: Malheiros, 2014.

MOTTA, Paulo Roberto. Transformação organizacional: a teoria e a prática de inovar. Rio de Janeiro: Qualitymark Ed., 2001.

PIRES, José Calixto de Souza; MACÊDO, Kátia Barbosa. Cultura organizacional em organizações públicas no Brasil. Revista de Administração Pública. Rio de Janeiro,v. 40, n. 1, p. 81-105, Jan./Fev. 2006.

ROBBINS, Stephen P. Comportamento Organizacional. 11. ed. São Paulo: Pearson Prentice Hall, 2005.

Como citar este artigo (Formato ABNT):

PINTO, A.G.B.; QUEVEDO, A.P.F. a INFLUÊNCIA DA Cultura Organizacional na Primeira Instância da Justiça Federal. Id on Line Revista Multidisciplinar e de Psicologia, Julho de 2016, vol.10, n 30, p. 332-345. ISSN 1981-1179.

Recebido: $15 / 05 / 2016$

Aceito: 25/05/2016 